\title{
Representation Component
}

National Cancer Institute

\section{Source}

National Cancer Institute. Representation Component. NCI Thesaurus. Code C41120.

Mechanism by which the functional and/or presentational category of an item may be conveyed to a user. Component of a Data Element Name that describes how data are represented (i.e. the combination of a Value Domain, data type, and if necessary a unit of measure or a character set.) The Representation occupies the last position in the Data Element name (i.e. rightmost). 